\title{
Se conoce que usted es "moderna": entre los márgenes de la modernidad
}

\author{
Vera-Rojas, María Teresa. Se conoce que usted es "moderna". \\ Lecturas de la mujer moderna en la colonia hispana de Nueva \\ York (1920-1940). Madrid-Frankfurt am Main: Iberoamericana- \\ Vervuert, 2018, 390 págs.
}

Argelia González Hurtado

St. Mary's College of Maryland

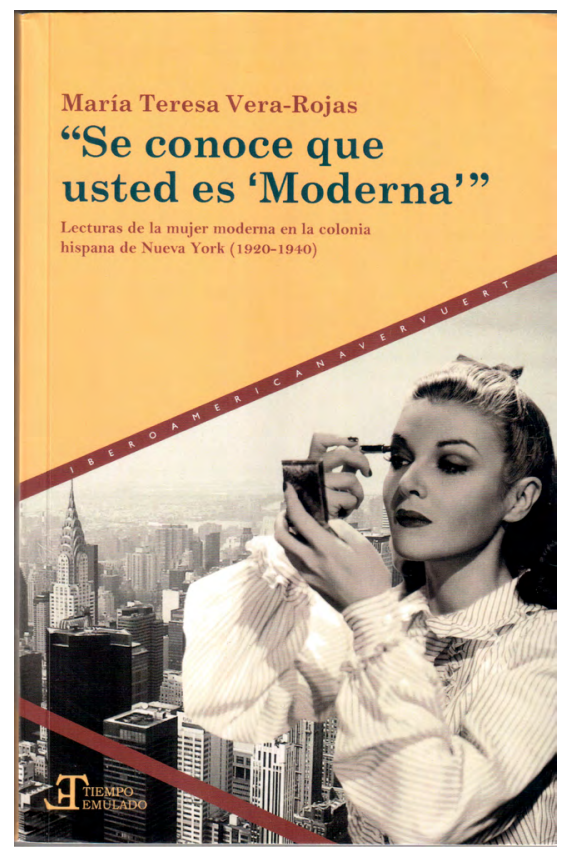

Los estudios de género, medios y cultura popular han generado en los últimos años un terreno fértil y creativo como lo demuestra el creciente número de monografías y colecciones publicadas, artículos y conferencias que ponen de relieve las diversas formas en que estos campos de estudio se relacionan. Ejemplo de estos trabajos son las compilaciones de artículos en Feminism in Popular Culture (Hollows y Moseley, 2006), Interrogating Postfeminism: Gender and the Politics of Popular Culture (Tasker y Negra, 2007), Máxima audiencia. Cultura popular y género (González Fernández y Clúa, 2011) y The Routledge Companion to Media \& Gender (Carter, Steiner y McLaughlin, 2015); o bien, la monografía de Angela McRobbie, The Aftermath of Feminism: Gender, Culture and Social Change. Así, el libro de Teresa Vera-Rojas Se conoce que usted es "moderna". Lecturas de la mujer moderna en la colonia hispana de Nueva York (1920-1940) más allá de ubicarse en este diálogo entre medios, cultura popular y género, añade una interesante lectura histórica sobre la diáspora latinoamericana en Estados Unidos, relevante por la política migratoria estadounidense actual.

Inspirada en la premisa de que la cultura popular es un escenario de luchas y negociaciones, Vera-Rojas explora crítica y detalladamente en este libro la manera en que la prensa en español y las prácticas culturales de su público construyeron la subjetividad de las mujeres hispanas como sujetos "modernos" en Nueva York, a principios del siglo XX. Vera-Rojas arguye que la subjetividad de las mujeres hispanas durante esta época fue producto de la apropiación, reapropiación y resignificación tanto de las representaciones de la feminidad como las del "American way of life" divulgadas por los medios de comunicación. De esta manera, propone que la mujer moderna hispana emerge como resultado de la intersección entre las prácticas y regulaciones que definían el modelo de la mujer moderna norteamericana (la flapper) con los elementos que configuraban su identidad cultural de origen. Para demostrar su argumento la autora ofrece un diligente análisis, tamizado por los Estudios Culturales y de Género, de la publicidad, cartoons, 
fotografías y de las secciones como los consejos de belleza y moda, los fotorreportajes, y las cartas de las lectoras divulgados en las tres publicaciones en español más importantes de Nueva York: el semanario Gráfica, el diario La Prensa y la revista cultural Artes y Letras.

Se conoce que usted es "moderna" puede sentirse repetitiva por momentos. Sin embargo, una lectura activa y concienzuda de los seis capítulos que componen esta monografía permitirá vislumbrar futuras líneas de investigación en las que se puede relacionar el estudio del activismo, belleza, ciudadanía, clase, capitalismo, consumo, diáspora, historia, maternidad, medios, memoria, moda, publicidad, racismo, recepción, salud, y tecnología en diferentes contextos históricos.

El capítulo I, "La mujer y los periódicos", examina las formas de regulación que ejercían la prensa y otras industrias culturales en la construcción de identidades durante el periodo de entreguerras. También pone atención a la manera en que los procesos de lectura y consumo permitían acceder, desde la periferia, al ejercicio de la ciudadanía y de la modernidad. Este primer capítulo termina con una interesante revisión tanto del feminismo de la época como del feminismo hispano en la metrópoli. En estas secciones se examinan las repercusiones de los disímiles discursos sobre el feminismo que se difundían en el público hispano, "el feminismo fue discutido y debatido, a la vez que celebrado y reapropiado en muchos textos publicados en los medios" (71).

Consciente de la diversidad de las mujeres que formaban la colonia hispana, la autora presta atención a los procesos de negociación cultural particulares del colectivo. Así en el capítulo II, "No aceptemos demarcaciones: lectoras, lecturas y publicaciones periódicas en la colonia hispana de Nueva York (1920-1940)" se indaga en los problemas culturales, raciales, políticos, socioeconómicos que enfrentaba la colonia hispana, en especial los que se derivaban de la fricción entre lo moderno y lo tradicional. A la par, explica las particularidades e influencia de los medios analizados: Gráfica, La Prensa y Artes y Letras. Prensa y lector son puestos bajo la lupa en este capítulo donde se establece que las condiciones históricas juegan un papel importante tanto para entender a los lectores y sus estrategias de recepción como para examinar los significados y mensajes divulgados por los medios.

Si bien este libro se centra en la prensa, cabe señalar que no se soslaya la importancia de otros medios como la radio, cinematografía o la publicidad, en la difusión del modelo de mujer moderna norteamericana, junto a otros discursos en torno a la feminidad. Esto se aprecia sobre todo en los capítulos III y IV. El capítulo III, "Imaginario de la mujer moderna” brinda un panorama de cómo los avances tecnológicos y científicos impactaron los espacios privados y domésticos, produciendo en la prensa discursos contradictorios entre los articulistas, la publicidad y las opiniones de los lectores. Demostrar los diversos discursos (publicitarios, editoriales, étnicos) que convergían en la construcción del cuerpo y de la identidad de la mujer hispana moderna es el objetivo del capítulo IV, “Tecnologías del cuerpo moderno". Además de los avances en ciencia y tecnología de la industria cosmética y de salud, el capítulo examina cuidadosamente los avisos publicitarios, los concursos 
de belleza, los consejos de salud, las cartas de las lectoras y las reseñas de moda. Particularmente, el análisis de los concursos de belleza arroja las contradicciones y las condiciones de vivir en el espacio marginal de la modernidad estadounidense. Vera-Rojas establece que estos certámenes de belleza inspirados en el concurso Miss America y auspiciado por asociaciones civiles, culturales y la prensa de la comunidad hispana "eran relevantes para las jóvenes concursantes porque suponía una forma de libertad y participación en las prácticas de la vida moderna norteamericana [...]" (p. 214). Desde luego, estos certámenes develaron el racismo y clasismo que conformaron los modelos de belleza favorecidos por la sociedad estadounidense y la comunidad hispana.

El enfoque de este estudio concibe a las mujeres de la colonia hispana en Nueva York como activas lectoras y consumidoras de lo popular. Se establece que la cultura popular proporciona un espacio de acción, identificación y experimentación identitaria en el que las mujeres, lejos de ser receptoras pasivas de lo popular, desarrollan una intensa actividad como creadoras y consumidoras activas. Esto se demuestra en los últimos capítulos V ("Las charlas de las lectoras") y VI ("La flapper en tres escenas), los cuales se enfocan en las posiciones de las lectoras ante los discursos de belleza, moda, salud y modernidad. En estos capítulos se destaca la heterogeneidad de las mujeres hispanas y sus diferentes posiciones en la sociedad estadounidense entre 1920 y 1940.

Como se ha señalado al principio de esta reseña, Se conoce que usted es "moderna" contribuye a enriquecer el estudio sobre el papel que juega la cultura popular en la difusión de ideas feministas y modelos de feminidad, y en analizar el espacio que los medios han proporcionado para la identificación y negociación de sus audiencias en la construcción de subjetividades. La lectura de este texto, además de proporcionar una mirada histórica a los factores que contribuyeron en la construcción de identidades de las heterogéneas comunidades hispanas en Estados Unidos, en y desde la migración, estimulará el estudio interdisciplinario de la cultura popular, el género, y los medios. 